\title{
A FORMAÇÃO INICIAL PARA O EXERCÍCIO DA DOCÊNCIA NOS ANOS INICIAIS DO ENSINO FUNDAMENTAL E A FORMAÇÃO DO PROFESSOR ALFABETIZADOR
}

\author{
Luciana Castro ${ }^{1}$, Beatriz de Basto Teixeira ${ }^{2}$ \\ ${ }^{1}$ Doutoranda em Educação no Programa de Pós Graduação da Faculdade de Educação da Universidade Federal de Juiz \\ de Fora - UFJF. Professora da Rede municipal de Juiz de Fora. E-mail: lu casttro@yahoo.com.br \\ ${ }^{2}$ Doutora em Educação pela Universidade de São Paulo - USP. Professora titular aposentada da Universidade Federal \\ de Juiz de Fora - UFJF e dos programas de pós-graduação em Educação e em Gestão e Avaliação da Educação Pública \\ da UFJF.
}

\section{RESUMO}

Este artigo pretende apresentar o percurso mais recente desenvolvido no contexto da formação de professores especialmente após a LDB. A partir de um breve panorama, objetiva trazer considerações relevantes sobre o processo formativo para a docência. Os dados aqui apresentados integram uma pesquisa maior, em andamento, de cunho qualitativo que investiga questões voltadas ao formador de professores. Para fins do presente texto, serão apresentados considerações sobre o cenário da formação inicial no Brasil, com base no mapeamento do estado do conhecimento desse campo em 10 (dez) periódicos que possuem Qualis/CAPES A1, com base na listagem divulgada em 2015, selecionados com apoio nos critérios de expressividade, considerando sua circulação nacional, no período de 2008 a 2018. 0 estudo indica que, passados mais de 20 (vinte) anos da promulgação da Lei de Diretrizes e Bases da Educação Nacional Brasileira, Lei no. 9.394/96, em que alguns avanços foram conquistados, ainda se enfrentam muitos desafios quanto à profissionalização docente, em especial, em relação as questões voltadas para a formação do professor alfabetizador. O que se percebe a partir da revisão de literatura sobre o tema, é ainda um modelo de formação prescritivo, com poucas condições de oportunizar ações pedagógicas voltadas para a aprendizagem de todos os estudantes brasileiros. Assim, a expectativa é que a discussão que pauta o artigo contribua com elementos a serem revisados a fim de impactar em melhor oportunidade de formação, em consequência, na ampliação de estratégias e das condições de aprendizagem dos alunos.

Palavras-chave: Formação Inicial. Alfabetização. Valorização do Magistério. Melhorias no Ensino. Relação teoria-prática.

\section{THE INITIAL TRAINING FOR THE EXERCISE OF TEACHING IN THE EARLY YEARS OF ELEMENTARY SCHOOL AND THE TRAINING OF TEACHER LITERACY}

\begin{abstract}
This article intends to present the most recent course developed in the context of teacher training especially after the LDB. From a brief panorama, it aims to bring relevant considerations about the formative process for teaching. The data presented here are part of a larger, ongoing, qualitative research that investigates issues geared to the teacher trainer. For the purposes of this text, considerations will be presented on the scenario of initial formation in Brazil, based on the mapping of the state of knowledge of this field in 10 (ten) journals that have Qualis/CAPES A1, based on the list disclosed in 2015, Selected with support in the expressiveness criteria, considering their national circulation, in the period from 2008 to 2018. The study indicates that, after more than twenty (20) years of the promulgation of the Law of guidelines and Bases of Brazilian national Education, Law no. 9.394/96, in which some advances have been achieved, there are still many challenges regarding the professionalization of teachers, especially in relation to the issues related to the formation of the literacy teacher. What is perceived from a wide literature review on the subject, is still a model of prescriptive training, with few conditions to opportunity pedagogical actions aimed at the learning of all Brazilian students. Thus, the expectation is that the discussion that guides the article, contributes with elements to be revised in order to impact on a better
\end{abstract}


opportunity of training, as a consequence, in the expansion of strategies and learning conditions of the students.

Keywords: Initial formation. Literacy. Valorization of the Magisterium. Improvements in teaching. TheoryPractice relationship.

\section{LA FORMACIÓN INICIAL PARA EL EJERCICIO DE LA DOCENCIA EN LOS AÑOS INICIALES DE LA ENSEÑANZA FUNDAMENTAL Y LA FORMACIÓN DEL PROFESOR ALFABETIZADOR}

\section{RESUMEN}

Este artículo pretende presentar el recorrido más reciente desarrollado en el contexto de la formación de profesores especialmente después de la LDB. A partir de un breve panorama, objetiva traer consideraciones relevantes sobre el proceso formativo para la docencia. Los datos aquí presentados integran una investigación mayor, en marcha, de cuño cualitativo que investiga cuestiones dirigidas al formador de profesores. A los efectos del presente texto, se presentarán consideraciones sobre el escenario de la formación inicial en Brasil, con base en el mapeo del estado del conocimiento de ese campo en 10 (diez) periódicos que poseen Qualis/CAPES A1, con base en la lista divulgada en 2015, seleccionados con apoyo en los criterios de expresividad, considerando su circulación nacional, en el período de 2008 a 2018. El estudio indica que, pasados más de 20 (veinte) años de la promulgación de la Ley de Directrices y Bases de la Educación Nacional Brasileña, Ley no. 9.394/96, en que algunos avances fueron conquistados, todavía se enfrentan muchos desafíos en cuanto a la profesionalización docente, en especial, en relación a las cuestiones dirigidas a la formación del profesor alfabetizador. Lo que se percibe a partir de la revisión de literatura sobre el tema, es aún un modelo de formación prescriptiva, con pocas condiciones de oportunizar acciones pedagógicas dirigidas al aprendizaje de todos los estudiantes brasileños. Así, la expectativa es que la discusión que pauta el artículo contribuya con elementos a ser revisados a fin de impactar en mejor oportunidad de formación, en consecuencia, en la ampliación de estrategias y de las condiciones de aprendizaje de los alumnos.

Palabras clave: Formación Inicial. Alfabetización. Valorización del Magisterio. Mejoras en la Enseñanza. Relación teoría-práctica.

\section{INTRODUÇÃO}

Este artigo apresenta-se como desdobramento de uma pesquisa de doutorado que investiga questões voltadas ao formador de professores. A partir de uma revisão da literatura, objetiva-se trazer considerações relevantes sobre o processo formativo para a docência, em especial, no contexto da formação inicial dos professores que atuarão nos primeiros anos de escolarização da infância. $O$ interesse pela temática relaciona-se ao entendimento de ser, a formação dos professores, uma das variáveis capazes de impactar em melhorias do ensino. Assim, na impossibilidade de abarcar o conjunto de medidas apresentadas como capazes de incidirem na efetivação desse propósito, a formação docente configura-se como uma das centrais (NÓVOA, 1991, 1999; BRZEZINSKI, 2008; GATTI; BARRETO; ANDRÉ, 2011; DOURADO, 2015). No âmbito legal, especificamente a partir da promulgação da Lei de Diretrizes e Bases da Educação Nacional (LDB) n. 9.394/96, o processo formativo dos professores figura-se de forma marcante nas políticas públicas educacionais no cenário brasileiro.

A fim de situar a temática em um contexto mais amplo, foi realizado um mapeamento do estado do conhecimento desse campo em 10 (dez) periódicos ${ }^{1}$ da área, que possuem Qualis/Capes A1, com base na listagem divulgada em 2015 selecionados com apoio nos critérios de expressividade, considerando sua circulação nacional, no período de 2008 , ano posterior ao meu trabalho de mestrado, no qual se fez uma revisão sobre formação docente, até agosto de 2018. Como se pode perceber, o

\footnotetext{
${ }^{1}$ Cadernos de Pesquisa; Educação e Realidade; Cadernos Cedes; Educação \& Sociedade; Educar em Revista; Revista Brasileira de Educação; Educação e Pesquisa; Educação em Revista; Avaliação; Revista Ensaio; Revista Educação em Foco.
} 
mapeamento foi realizado ao longo dos anos da pesquisa de doutorando e somou-se aos dados levantados na ocasião da produção de dissertação. Portanto, os estudos sobre o processo formativo do professor dos anos iniciais da Educação Básica compreendeu um tempo significativo de pesquisa sobre a temática. Além desses periódicos, recorreu-se ainda a leitura de publicações organizadas em livros e eventos reconhecidos no campo da formação de professores.

Com base nesse levantamento pode-se afirmar que a importância da formação de professores dos anos iniciais do Ensino Fundamental em cursos de graduação de nível superior conclamou-se no Manifesto dos Pioneiros da Escola Nova. Contudo, ainda que presente na história do magistério no Brasil, somente em 1996 foi instituída na realidade educacional brasileira pela LDB. Até então, apesar da existência dos cursos de Pedagogia desde 1939, a Escola Normal e, em alguns estados do país e por estes financiados, os Centros Específicos de Formação e Aperfeiçoamento do Magistério eram as principais referências para a formação dos professores dos anos iniciais. Cabia ao curso de Pedagogia a formação de especialistas para ocuparem os cargos técnicos em educação e de professores para atuarem na Escola Normal em nível médio (BRZEZINSKI, 2008).

Interessante destacar que a primeira regulamentação do curso de Pedagogia foi realizada a partir da formação de bacharéis nas poucas universidades existentes, acrescentando um ano com disciplinas da área da educação para a obtenção do título de licenciatura. Assim, a Pedagogia seguiu a estrutura conhecida como " $3+1$ ", a saber, 3 (três) anos de bacharelado e 1 (um) ano de matérias pedagógicas (Didática Geral, Didática Especial, Psicologia da Educação e Administração Escolar). Desse modo, o professor era formado tendo como base os conteúdos que iria ensinar em detrimento do "como" ensinar (OLIVEIRA, 2010). Com efeito, o quadro de professores à frente da formação docente para os anos iniciais da Educação Básica constituía-se por profissionais que, em maioria, não apresentavam nenhuma vivência da prática educativa dos anos iniciais. Essa realidade acarretou um modelo de formação prescritivo, com poucas condições de oportunizar uma vivência da docência como autônoma.
Com a publicação da Lei de Diretrizes e Bases da Educação Nacional, no. 9394, de dezembro de 1996, mudanças foram propostas para as instituições e cursos de formação de professores. Destaca-se a indicação para elevar em nível superior a formação inicial para a atuação na Educação Básica. De acordo com Mercado, em entrevista cedida à Souza e Zibetti (2014), frente a essa orientação legal, percebe-se que o Brasil acatou o movimento internacional de universitarização. Sarti (2012), Bello (2014) e Butlein (2015) explicam que a universitarização do magistério teve em seu bojo a expectativa de que o contato dos professores com os saberes acadêmicos poderia proporcionar uma elevação formal de qualificação a qual resultaria na ampliação de competências profissionais, elevando, assim, a qualidade do ensino. Contudo, de acordo com os dados levantados, parece que ainda é comum uma lógica formativa reduzida ao discurso teórico (ALTET; PERRENOUD; PAQUAY, 2003; GATTI; BARRETO, 2009; MENEZES; TROMPIERI FILHO; BRAGA, 2014) em detrimento dos saberes da prática escolar. Assim, a relação teoria e prática mantém-se rompida na formação dos futuros professores para a docência dos anos iniciais. Portanto, o discurso que pautou o debate dos anos de 1980, baseado na busca pela superação às críticas à incapacidade do modelo vigente viabilizar uma formação sólida ${ }^{2}$ e sustentado ainda devido a necessidade de dar uma resposta à tensão gerada pelo descompasso entre a expansão da rede pública de ensino e o "insucesso" de grande parte dos alunos atendidos nesse setor, ainda não se efetivou no cenário brasileiro. $O$ que se percebe é que passados mais de 20 (vinte) anos da promulgação da LDB, em que alguns avanços foram conquistados, ainda se percebe muitos desafios quanto à profissionalização docente, em especial para a atuação dos professores no processo de alfabetização inicial das crianças brasileiras. Frente a esse contexto, justifica-se este artigo que carrega a expectativa de fomentar o debate e contribuir com a possibilidade de apresentar elementos que podem ser revisados a fim de impactar em melhor oportunidade de formação e, em consequência, na ampliação de condições pedagógicas que podem incidir na aprendizagem dos alunos.

\footnotetext{
${ }^{2}$ Entendida como aquela que contempla a relação dialética entre os diferentes saberes do campo da docência, dentre eles os produzidos pela academia e pela prática profissional (TARDIF, GATTI, NÓVOA, FREIRE).
} 


\section{MÉTODOS}

Este artigo apresenta-se, como já mencionado, como desdobramento de uma pesquisa maior realizada no âmbito de uma pesquisa de doutoramento ${ }^{3}$. Para o referido estudo, empreendeu-se uma revisão bibliográfica sobre o processo formativo docente, de modo especial, sobre a formação inicial do professor dos anos iniciais da escolarização, no período de 2008 a agosto de 2018. Contudo, como essa temática era discussão central da dissertação de mestrado, a qual foi produzida nos anos de 2005 a 2007, a revisão de literatura sobre o tema soma mais de duas décadas (CASTRO, 2013). Dito isso, importante destacar que trata-se de um artigo construído tendo como base estrutural o levantamento bibliográfico desenvolvimento ao longo da trajetória acadêmica.

O estudo que trata este artigo, classificase como uma revisão bibliográfica, cujo objetivo é apresentar o percurso mais recente e tecer apontamentos relevantes sobre o contexto da formação de professores especialmente após a LDB. A consulta mais recente, ou seja, desenvolvida no período de 2008 a 2018, envolveu a consulta nos 10 periódicos que possuem Qualis/CAPES A1, com base na listagem divulgada em 201, já referidos anteriormente. Os artigos foram selecionados com base no título, em seguida foram delimitados a partir da leitura dos resumos e a partir das expressões "Formação inicial", "Política de Formação Inicial" como palavras-chave. Por fim, procedeu-se a leitura do artigo completo. Em um primeiro momento fezse uma "leitura flutuante" para, posteriormente, exercitar uma leitura mais cuidadosa. Nesse processo, foi-se construindo um corpus com o objetivo de se ter uma amostra representativa de como a formação inicial vem sendo tratada no campo da pesquisa. A partir das leituras feitas, anotou-se os aspectos destacados nos textos. Posteriormente, estabeleceu-se um modelo processual de análise do texto onde foi possível destacar os padrões e contrastes dos significados visíveis e assim, foi possível construir a contextualização do campo da formação. Com efeito, foi possível observar a incidência de

\footnotetext{
${ }^{3}$ Aprovada pelo Comitê de Ética de Pesquisa com Seres Humanos da instituição em que a pesquisa se desenvolve conforme parecer número 1.715.141;

${ }^{4}$ De acordo com Bardin (2009, p. 68) diz respeito a uma leitura geral do texto para ter ciência do todo. Seria "uma primeira leitura, a qual podem surgir intuições que podem ser formuladas em hipóteses.
}

pesquisas e produções acadêmicas que revelaram descontentamento em relação à formação inicial instituída. As pesquisas consideradas nesse trabalho apresentaram constatações semelhantes às encontradas na ocasião da produção de dissertação ${ }^{5}$, o que sinaliza a recorrência da insatisfação com o modelo de formação para a docência e, também, ao que parece, poucas mudanças para reestruturar efetivamente esse modelo foram feitas.

Por fim, é preciso realçar que embora a estrutura de busca realizada nos periódicos possa não dar conta de captar todos os artigos referentes à formação inicial, ela ilustra a situação desse momento da formação docente na realidade brasileira.

\section{RESULTADOS}

Por meio da análise dos dados apresentados a partir do mapeamento empreendido sobre o campo da formação docente, pode-se afirmar que a falta de investimento e a valorização do magistério, corrobora com um cenário onde há um crescente número de analfabetos funcionais. Trata-se de indivíduos que que não apresentam habilidades para compreenderem um texto simples (SOARES, 2016), questão muito séria se levarmos em conta que isso traz prejuízos a todo o processo de escolarização.

Desenha-se assim o principal contorno para o fracasso escolar. Nesses termos pode ser entendido como um fenômeno produzido em grande parte pela dificuldade dos alunos se apropriarem e fazerem uso do material escrito. Situação que não é uma realidade exclusiva das escolas públicas, mas que, inclusive pela falta de suporte sócio financeiro de seu público, recai sobre ela. Sendo assim, é notório em seu interior, situações de exclusão precoce de crianças das camadas populares quer seja pela sua permanência, sem que isso gere, de fato, aprendizagem formal dos conteúdos valorizados culturalmente, quer seja pela evasão. O fato é que os professores expropriados de condições para atuarem, inclusive pela negligência formativa aos saberes imprescindíveis para o fazer pedagógico, reforçam ainda que de forma não intencional, a ineficácia dos processos pedagógicos e fins educacionais. Nesses termos,

\footnotetext{
${ }^{5}$ O levantamento da arte realizado para o desenvolvimento da pesquisa de Mestrado compreendeu o período da aprovação da LDB de 1996 até os anos de 2007.
} 
é possível afirmar que a alfabetização pode ser entendida como um nó na vida de muitos alunos. Trazer à tona essa discussão implica tratar da incapacidade da escola em cumprir seu papel. Dito isso, cabe esclarecer que longe de culpabilizar o professor, em especial o alfabetizador, a intenção é fomentar o debate sobre a importância de um investimento maciço em seu processo formativo e nas condições que acometem a sua atuação no magistério. Dessa forma, faz-se fundamental a defesa pela revisão da formação inicial e a garantia da formação continuada.

Considerada como indutora de elementos reflexivos que possibilitam aos professores analisarem suas ações cotidianas, indagarem sobre suas possibilidades de intervenção, examinarem as razões do que se passa na sala de aula, fortalecendo sua autonomia, estudiosos como Nóvoa (1995; 1998), Schön (1995) e Freire (1997) defendem a formação continuada como condição para melhorias na educação. Para tanto, esse momento da formação precisa proporcionar a vivência dos conhecimentos necessários para que os profissionais do ensino possam conduzir suas atividades a partir de um processo dialético de reflexão na e sobre a prática. Nessa perspectiva, refuta-se o modelo clássico de formação continuada pautado em ações pontuais, isoladas, organizadas, desconsiderando uma sólida formação teórica e epistemológica, ao se reduzirem as prescrições funcionais do fazer pedagógico que, associadas à descontinuidade política, fortalecem uma formação fragmentada no que tange à relação teoria-prática.

No entanto, essa foi a perspectiva adotada no país a partir das produções empreendidas para o estudo. Observou-se um crescente investimento do governo federal em políticas de formação continuada dos professores alfabetizadores ao longo dos anos de 1996, em decorrência dos preceitos da LDB até 2016, quando o país vivenciou (e vivencia) retrocessos sem precedentes em diversos setores fruto de uma crise política. Contudo, tendo como uma realidade a falta de tratamento adequado na formação inicial, questão apresentada anteriormente, as ações organizadas tinham contornos nítidos de formação compensatória.

Estudos indicam que embora a formação continuada docente no Brasil seja reconhecida como um direito legal, ela não se traduziu na oportunidade de vivência dos conhecimentos necessários para que o professor realize sua tarefa a partir de uma reflexão crítica na e sobre sua prática (GARCIA, 1999; IMBERNÓN, 2011). De um modo geral, o que se vê nas propostas de formação continuada é a teoria sendo estruturada sobre um discurso vazio que ocorre a partir da implantação de programas ou cursos, cujo formato pauta-se em encontros que visam oferecer conteúdos e técnicas de forma prescritiva e funcional. Dessa forma, esse momento formativo, na maioria das vezes, centrou-se (e centra-se) em ações pontuais, isoladas e de curta duração, que nada ou pouco contribuem para romper com a relação de poder em torno do saber sob os moldes da "educação bancária" (FREIRE, 1997) comum ao nosso sistema de ensino. Consoante com esse formato, estruturam-se a partir do caráter individual da formação nos quais o indivíduo é isolado de seu contexto de atuação, o que traz prejuízos ao desenvolvimento profissional.

Nessa perspectiva, afigurou-se no processo de formação, um modelo pautado na fragmentação do processo formativo e na falta de integração teoria-prática, princípio fundamental para o desenvolvimento profissional. Refutar esse modelo nos aproxima da defesa a favor de uma proposta formativa para a docência, capaz de favorecer a reflexão conjunta do trabalho pedagógico a partir da valorização dos saberes docentes (CASTRO, 2013).

Nesses termos, considerando a problemática do processo de formação, é importante trazer para a discussão o desafio posto ao professor alfabetizador. No interior das escolas, são os professores que tendam dar conta de sua tarefa do melhor modo possível em meio à realização do trabalho em salas de aulas numerosas, em escolas com problemas vinculados à infraestrutura e a vivência de um tempo de lazer escasso. Soma-se a progressiva deterioração da imagem profissional, ao malabarismo financeiro para sobreviverem com parcos salários - aspecto que os leva a possuírem outras atividades remuneradas além da docência ou a enfrentarem um tempo de trabalho diário desumano marcado pela rotina de um 'caixeiro viajante'.

Diante desse quadro, a discussão proposta implica em denunciar, mais uma vez, a urgente e estimada revisão das condições e contradições dos sistemas de ensino do país ofertados a sua população. Mais que isso, em propor ações capazes de influenciar em uma 
mudança de rota do setor educacional. Em meio a esse entendimento, uma medida importante a ser considerada refere-se às condições que acometem o magistério, dentre elas a formação do professor, em especial, na formação inicial. Isso porque a falta de uma formação que trate do que e como ensinar leva a perda de oportunidade de intervenções essenciais para a condução de novas aprendizagens. Portanto, entende-se que oportunizar ao professor os conhecimentos fundamentais para realizar seu trabalho com segurança pode ser a "matéria prima para a transformação possível" (PATTO, 2015).

Considerando o momento em que o Brasil atravessa, o qual é marcado, inclusive, pela escassez de investimento no setor educacional, a perspectiva de consolidação de uma política de valorização do magistério que atrele formação, condições de trabalho e remuneração sinaliza muitos desafios pela frente. Ainda que o cenário atual seja condizente com dilemas históricos que se complexificam na educação brasileira, enquanto "profissionais da esperança" (FREIRE, 1992), é preciso lutar pela construção de uma lógica mais assertiva no campo formativo do magistério. No tocante à alfabetização, sigamos empenhados no esforço em se criar estratégias capazes de organizar um determinado conhecimento e dispor de formas diferentes para que o direito à educação se efetive. Por consequência, acarretará em melhorias da qualidade da alfabetização das crianças brasileiras.

\section{DISCUSSÃO}

O ano de 1986 marca o processo formativo para a docência no Brasil. Foi nesse ano que o Conselho Federal de Educação aprovou a reformulação do curso de Pedagogia, que passou a facultar a formação para a docência de 1a a 4a séries do Ensino Fundamental. Com a publicação da Lei de Diretrizes e Bases da Educação Nacional, no. 9394, de dezembro de 1996, mudanças foram propostas para as instituições e cursos de formação de professores. Destaca-se a indicação para elevar em nível superior a formação inicial para a atuação na Educação Básica.

Sarti (2012), Bello (2014) e Butlein (2015) explicam que a universitarização do magistério teve em seu bojo a expectativa de que o contato dos professores com os saberes acadêmicos poderia proporcionar uma elevação formal de qualificação a qual resultaria na ampliação de competências profissionais, elevando, assim, a qualidade do ensino. Contudo, como resposta ao processo de reforma do Estado calcada na internacionalização da economia e no predomínio do mercado como principal força reguladora das relações humanas, as políticas educacionais, a partir da década de 1990, foram orquestradas sob uma visão mercadológica de educação, a qual implicou prejuízos, inclusive para o processo formativo para a docência, dentre eles, o de sucateamento das instituições públicas de ensino frente à expansão das instituições privadas.

Desse modo, o prenúncio da formação em nível superior, a fim de elevar a qualificação dos profissionais dedicados à Educação Infantil e aos anos iniciais do Ensino Fundamental, resultou no fechamento da maior parte dos cursos de formação em nível médio, diante da busca de milhares de professores pela diplomação no novo nível exigido. A questão é que esse fator, inicialmente, não atendeu à expectativa de viabilizar o acesso dos professores dos anos iniciais da Educação Básica à universidade. A massificação do ingresso no Ensino Superior articulada à "brecha" permitida pelo texto legal da LDB/1996, em seu artigo 62, ao instituir uma nova agência formadora, acarretou o desvio da formação inicial para os Institutos Superior de Educação (ISE), que, no ano de 1999, por meio da Resolução CP no 115 (Conselho Nacional de Educação), criou o Curso Normal Superior (CNS).

A orientação legal era que o CNS fosse oferecido nos ISE na modalidade presencial ou a distância, a partir de parcerias realizadas entre as instituições universitárias e os sistemas de ensino, tendo em vista garantir a formação de seus professores em exercício. Pesou como principal crítica ao CNS o caráter técnicoprofissionalizante devido, fundamentalmente, à negligência de um conjunto de dimensões do campo teórico, prático, simbólico, ético, científico, didático, cultural, estético, tecnológico, social, enfim, de um vasto campo de saberes, conhecimentos e habilidades (TARDIF; LESSARD, 2008) importantes para o desenvolvimento profissional do professor. Segundo Freitas (2003), a criação de novas instâncias para a formação docente atendeu aos interesses de organismos internacionais de diferentes países, tendo em vista diminuir os altos custos coma pesquisa, atividade central na formação desenvolvida nas universidades. 
O contexto de reforma do Estado pautada no entendimento da educação escolar como um produto capaz de responder às exigências do desenvolvimento econômico e do mercado, associada ao propósito de ampliar a formação daqueles que já atuavam nos anos iniciais da Educação Básica, mas ainda não tinham formação superior, acarretou, em um primeiro momento, na expansão desordenada dos cursos de formação em nível superior e na ampliação da educação à distância. Corroborando com Barreto (2015), o efeito foi o crescimento da iniciativa privada que passou a ocupar espaço central no campo formativo e da modalidade a distância, características que se apresentam de forma preocupante no cenário dos cursos de formação para a docência.

O avanço da expansão da iniciativa privada implicou uma visão restrita de educação vinculada a um "[...] "bem de mercado", como uma mercadoria, cujo valor se define em função do tipo de serviço, do prestador do serviço e da possibilidade de compra pelo consumidor/usuário" (BARRETO, 2015). Nesses termos, o que se percebe é uma concepção de direito privado do exercício educacional (CURY, 2014). Outro ponto a ser considerado é que as instituições privadas de ensino superior, voltadas, em maioria, aos interesses de mercado, multiplicam seus campi Brasil afora sem dar o devido tratamento à pesquisa, função inerente ao ensino superior. "Tampouco se caracterizam por um zelo especial em relação às atividades de ensino" (BARRETO, 2015, p. 684).

Sobre o ensino a distância, importante destacar que sua regulamentação, por meio da LDB de 1996, viabilizou novas possibilidades de desenvolvimento da EAD, implicando um campo fértil para se expandir em todo território brasileiro. Em 2006, no período em que Fernando Haddad esteve à frente do Ministério da Educação no governo do então presidente Luiz Inácio Lula da Silva (2003- 2011), tendo como justificativa frear a ampliação dessa modalidade de ensino na esfera privada, foi criada a Universidade Aberta do Brasil (UAB), uma política de governo na formação docente, desenvolvida com recursos do Fundo Nacional de Desenvolvimento da Educação (BRASIL, 2006).

À UAB coube o mérito de ter favorecido a profissionalização do magistério ao acolher um expressivo número de professores leigos ou de professores sem curso superior. Agrega-se a essa política de formação o mérito de ter, também, garantido formação continuada aos já graduados. Além disso, ela viabilizou o fácil acesso ao nível superior para jovens em regiões comprometidas geograficamente com esse nível de ensino. Por tudo, pode ser considerada, em certa medida, uma ação que favoreceu a expansão do número de futuros professores em contexto de previsão de um "apagão". Porém, em contrapartida, configurou-se como uma expansão desenfreada que vem despertando inúmeras preocupações no cenário acadêmico.

Os estudos apresentados por Gatti e Barreto (2009), Barreto (2015) e Gatti (2013) ilustram essa situação. Segundo as pesquisadoras, a formação inicial oferecida pela UAB trouxe problemas decorrentes da dispersão do desenvolvimento sociocultural dos futuros professores da vivência universitária, comunitária e institucional que preza o cotidiano coletivo de estudos e relações escolares; da falta de articulação de conhecimentos novos provenientes de pesquisa, o que constitui o cerne das atividades de caráter universitário; do baixo amadurecimento acadêmico frente à rápida expansão; da falta de estruturas, como bibliotecas e laboratórios, que constituem meios indispensáveis para uma sólida formação. Somase, ainda, a improvisação em relação ao projeto pedagógico que, em maioria, tende a reproduzir os moldes da formação presencial. Barreto (2015) menciona que da forma como se estruturou, a formação resvala para um pragmatismo reducionista que desdenha da fundamentação das questões mais abrangentes envolvidas no processo educativo. Por fim, o exercício da tutoria também é destacado nessa problemática conjuntura (BARRETO, 2015; GATTI, 2008; 2010). Isso porque a forma como vem sendo realizada representa uma das mais novas configurações do exercício e da desqualificação da docência, sobretudo, pelas condições de trabalho indevidas marcadas pela sobrecarga de trabalho e precariedade das formas de contratação e de remuneração.

Posto isso, importante dar visibilidade a estudos, como o realizado por Oliveira (2010), que apontam outra face dessa modalidade de ensino ao salientar a qualidade de projetos desenvolvidos em cursos à distância e seus desdobramentos na transformação das práticas educacionais de parte dos professores que já atuavam nos anos iniciais da Educação Básica. $\mathrm{Na}$ mesma vertente, o artigo de Bruno e Teixeira (2010) indica que, ainda que o emprego da 
educação à distância (EAD) em larga escala para a formação de professores ocorra em meio a um intenso debate pela comunidade acadêmica que demonstra preocupação com a qualidade da formação que se oferece por essa via, é preciso se considerar que algumas experiências valem a pena. Afirmam isso ao refletirem sobre as possibilidades de inclusão social e inclusão digital oferecidas nessa modalidade, tendo em vista os dados de uma pesquisa de monitoramento de um Curso de Pedagogia à distância realizado na Faculdade de Educação da Universidade Federal de Juiz de Fora, Minas Gerais. As autoras afirmam que embora os resultados sejam sutis e que se exija mais pesquisas na linha de avaliação dos cursos desenvolvidos na modalidade, os indícios produzidos parecem positivos.

Contudo, essa perspectiva não é predominante nas pesquisas consideradas no inventário bibliográfico realizado (BARRETO, 2015; GATTI, 2008; 2013; GATTI; BARRETO, 2009; BRZEZINSKI, 2008). O que se percebe é que a modalidade a distância em programas e políticas de formação de professores apresenta-se em um cenário marcado pela fragilização do processo formativo docente, o que pouco contribui para melhorias no desenvolvimento profissional e valorização do magistério.

Em relação à intenção de que ao se instituir a UAB fosse possível frear a ampliação dessa modalidade de ensino na esfera privada, Freitas (2014) e Bello (2014) esclarecem que não foi o que ocorreu visto que as matrículas cresceram mais na rede privada que na UAB. Desse modo, os dados relativos aos cursos a distância demonstram a privatização da formação, já que a maior parte das matrículas em cursos de pedagogia estão no setor privado.

Em linhas gerais, observa-se que a UAB trouxe novos desafios à formação docente no país. De um modo geral, é preciso reconhecer que o forte apelo a educação à distância em detrimento da presencial acarretou políticas educacionais cujas medidas deveriam ter caráter emergencial, sendo adotadas como permanentes. Assim, o incremento da formação docente em nível superior na referida modalidade compõe o cenário de descontentamento com os arranjos do processo formativo para o magistério dos anos iniciais da Educação Básica. Mais que isso, a disseminação da UAB colocou a participação das universidades condicionada à adesão de regras impostas pelas planilhas orçamentárias (LAPA; PRETTO, 2010).
Para Lapa e Pretto (2010), se por um lado as instituições universitárias aderem ao empenho nacional da expansão e democratização do ensino superior na formação de professor, por outro, o direcionamento dos projetos políticopedagógicos dos cursos aos recursos financeiros inviabilizam muitas das perspectivas teóricas e práticas pedagógicas objetivadas. Desse modo, o "paradigma" dos modelos promovidos pela UAB em escala nacional, desdobram-se, inclusive na precarização do trabalho docente.

Ao lado da tensão posta pelo emprego da modalidade à distância na formação docente e das ações de privatização, a formação inicial presencial realizada na universidade é outro fator que denota quão complexa é a realidade do processo formativo no Brasil. Nessa discussão cabe considerar que, indiscutivelmente, a universidade devido a sua condição de assegurar a tríade da pesquisa, ensino e extensão, consolidou-se como instituição clássica de formação inicial de professores. No entanto, paira uma incerteza quanto à capacidade de atuação dos professores universitários como formadores de professores para a Educação Básica. A questão que se apresenta nas pesquisas empreendidas indica que elevar a formação dos professores da Educação Infantil e dos anos iniciais da escolarização para a universidade vem resolvendo o problema quantitativo da formação inicial de professores, mas ainda não deu conta, de forma satisfatória, da qualificação do exercício da docência.

Uma análise geral da formação inicial docente no Brasil, por meio das produções acadêmicas empreendidas nesse artigo revelam que, para além das críticas em torno da criação dos ISE e do CNS, bem como da expansão da EAD, a formação inicial oferecida de forma presencial no âmbito da universidade também não se apresenta de forma satisfatória. Em geral, as produções indicam que a formação docente em nível superior não tem cumprido bem o seu papel. Ao que parece, as possíveis interrogações tecidas pela universidade a respeito do seu papel na formação do professor, ainda não viabilizou mudanças estruturais em seu modelo original conhecido como " $3+1$ ", cuja principal característica é o distanciamento entre os conteúdos a serem ensinados em detrimento do "como" devem ser ensinados, em decorrência, inclusive, de um professor formador que desconhece a prática educativa dos anos iniciais. Nesse sentido, é possível afirmar que, com base 
na amostragem dos artigos que trataram diretamente da formação inicial, parece haver certa convergência da comunidade educacional em torno do pressuposto de que os cursos para tal fim, de modo especial o de Pedagogia, o qual passou a ser o principal responsável pela formação dos professores atuantes na escolarização da infância, “(...) não dão conta de capacitar os professores no que se refere a tarefas básicas que têm de enfrentar os docentes no cotidiano da escola e que, no mínimo, se esperava que fossem atendidas pela formação inicial" (BARRETO, 2015, p. 698). A entrevista concedida pela pesquisadora mexicana Ruth Mercado Maldonado em outubro de 2013 à Souza e Zibetti (2014), ilustra essa afirmação. A pesquisadora afirma que a universidade ignora

[...] várias coisas que
podem ajudar o professor
simplesmente a saber
mais, a ampliar seus
conhecimento sobre a
docência, sobre a escola e
os processos de
escolarização. Muita coisa
está sendo produzida o
tempo todo na pesquisa,
mas embora isso circule
entre nós, não sabemos
como traduzir aos
professores. Pretendemos
levar as teorias e os
produtos da pesquisa tal
qual eles são elaborados
na academia. Depois
dizemos: Não
compreendem, não leem!"
(SOUZA; ZIBETTl, p. 259).

A afirmação acima dialoga com o que as pesquisas brasileiras indicam: as políticas de formação inicial não resolveram os problemaschave da formação docente, dentre os quais se destacam o desafio do diálogo entre a pesquisa acadêmica e a escola; entre o entrecruzamento da teoria e da prática (GATTI; BARRETO, 2009; ANDRÉ, 2015; NÓVOA, 1999 ; VAILLANT, 2015).

Uma amostra nacional apresentada na pesquisa realizada por Gatti e Barreto (2009) evidencia de modo mais específico essa presunção. Os dados produzidos indicaram que na maioria dos cursos destinados à formação inicial dos professores da Educação Básica não há disciplinas voltadas às metodologias de ensino e, quando oferecidas, são ministradas por professores que não têm conhecimento do trabalho com crianças. A disciplina de alfabetização, fundamental na escolarização da infância, ilustra essa situação. Os dados da referida amostra indicam que, quando oferecida na Pedagogia, tem à frente professores que, pela distância do cotidiano escolar, não abordam a discussão de como alfabetizar as crianças, tratando a disciplina de forma reduzida ao discurso teórico.

Menezes et al. (2014) trazem dados que confirmam a preocupante situação em que a formação docente se encontra. As pesquisadoras recordam-se que ao acompanharem a política de alfabetização no município de Sobral, Ceará, no início dos anos 2000, constaram que não havia proposta estruturada de formação inicial que contemplava a alfabetização. $\mathrm{Na}$ realidade hodierna embora exista na formação inicial disciplina com foco na alfabetização, é optativa aos futuros professores.

A vivência de Magda Soares, que desde 2007 realiza um trabalho voluntário de desenvolvimento profissional de professores e de busca de melhoria da qualidade da educação em uma rede pública de ensino de um município mineiro, converge com os dados evidenciados por Gatti e Barreto (2009) e com a problemática sinalizada por Menezes et al. (2014).

Em Lagoa Santa,
frequentemente eu me
surpreendia com quanto
de essencial as professoras
não sabiam a respeito do
processo de alfabetização
e letramento, a verdadeira
revelação que era para
elas compreender os
processos cognitivos e
linguísticos que seus
alunos experimentavam
tentando aprender a ler e
a escrever, e como as
dificuldades que crianças
enfrentavam eram muitas
vezes geradas por
ausência de um orientação
adequada e pertinente
que não tinham
fundamentos para dar
(SOARES, 2014, p. 171).

A situação retratada por Soares a partir de uma realidade local desvela o que os estudos, os quais estão sendo produzidos sobre a temática denunciam que a universidade arraigada em uma tradição conteudista de formação docente 
instaura um fosso entre os conteúdos da formação e as exigências para o desempenho da docência, ou seja, entre o campo da formação e o campo da atuação (VAILLANT, 2015; BUTLEN, 2015; GATTI 2010; 2015). Nóvoa (2017) e Barreto (2015) contribuem com essa discussão ao afirmarem que a despeito de muitas reformas educacionais, a formação inicial em nível superior ainda se mantém presa aos velhos hábitos que marcaram a abertura do curso de Pedagogia. Assim, ainda que seja verdade que existe no espaço universitário uma retórica de "inovação pautada na ideia de professor reflexivo", de investigação-ação, a universidade ainda é uma instituição conservadora (NÓVOA, 2017). Nesses termos, permanece pautada na lógica de que, para ser um bom professor, basta que se domine os conhecimentos das disciplinas as quais devem ser ensinadas. Portanto, é urgente uma formação inicial que abarque as questões voltadas ao porquê ensinar, o que ensinar e como ensinar (GATTI; BARRETO, 2009; DINIZ-PEREIRA, 2011, ANDRÉ, 2015).

No tocante a alfabetização, interessante destacar que pesquisadores como Soares (2014) indicam que a formação inicial não dá conta de preparar o professor alfabetizador. Mencionam que, em maioria, ao assumirem turmas de alfabetização esses professores demonstram desconhecimento de saberes indispensáveis a tarefa de alfabetizar. Portanto, em geral, não possuem conhecimento acerca das habilidades e conhecimentos cruciais para conduzir a apropriação do sistema de escrita alfabético. Em maioria não reconhecem as regras de funcionamento e propriedades do referido sistema, desconhecem os pressupostos metodológicos para fundamentar formas de alfabetizar e, como já mencionado, não apresentam conhecimentos sólidos para sistematizar a alfabetização de modo a favorecer que os aprendizes se tornem usuários da língua materna com autonomia. Essa realidade impacta no fortalecimento dos processos de desqualificação, intensificação e degradação do trabalho do professor.

Frente a isso, faz-se urgente a consolidação de uma política de valorização do magistério que atrele a política de formação, às condições de trabalho e de remuneração. Com efeito, por meio dos dados levantados no estudo bibliográfico empreendido, é importante considerar a necessidade de se revisar a formação inicial dessa categoria como uma importante medida de valorização profissional.

\section{AGRADECIMENTOS}

Agradecemos à Coordenação de Aperfeiçoamento de Pessoal de Nível Superior (CAPES) pelo financiamento da pesquisa.

\section{REFERÊNCIAS}

ALTET, Marguerite; PERRENOUD, Phillipe; PAQUAY, Leopol (org.). A profissionalização dos formadores de professores. Trad. Fátima Murad. Porto Alegre : Artmed, 2003.

ANDRÉ, Marli E. D. A. Espaços Alternativos de formação docente. In: GATTI, Bernadete Angelina et. al. Por uma revolução no campo da formação de professores. São Paulo: Editora Unesp, 2015.

BARDIN, L. Análise de Conteúdo. Lisboa, Portugal; Edições 70, LDA, 2009.

BARRETO, Elba Siqueira de Sá. Políticas de Formação Docente para a educação básica no Brasil: embates contemporâneos. Revista Brasileira de Educação. v. 20, n. 63, p. 679-701, jul./set. 2015.

BELLO, Isabel Melero. Cursos e Programas Especiasi no Mercado da Formação Docente. In: SOUZA, Denise Trento Rebello de; SARTI, Flávia Medeiros (orgs.). Mercado de formação docente: constituição, funcionamento e dispositivos. Belo Horizonte : Fino Traço, 2014.

BRASIL. Decreto no. 5.800, de 8 de junho de 2006. Dispõe sobre o Sistema Universidade Aberta do Brasil - UAB. Diário oficial [da] República Federativa do Brasil, Poder Executivo, Brasília, DF, 10 jun. 2006. Disponível em: http://www.planalto.gov.br/ccivil 03/ Ato20042006/2006/Decreto/D5800.htm. Acesso em: 27 ago. 2016.

BRASIL. Lei no. 9.394/96, de 20 de dezembro de 1996. Estabelece Diretrizes e Bases para a Educação Nacional. Diário Oficial da República Federativa do Brasil. Brasília, DF, 23 dez. 1996.

BRZEZINSKI, Iria. Políticas Contemporâneas de formação de professores para os anos iniciais do ensino fundamental. Revista Educação e Sociedade, Campinas, SP, v. 29, n. 105, p. 1139- 
1166, set./dez. 2008. Disponível em: http://www.scielo.br/scielo.php?pid=S01017330 2008000400010\&script=sci abstract\&tlng=pt. Acesso em: 04 jul. 2016.

BUTLEN, Max. Os desafios da participação dos profissionais da escola na formação dos professores: um olhar sobre a experiência francesa de universitarização e profissionalização docente. In: GATTI, Bernadete Angelina et. al. Por uma revolução no campo da formação de professores. São Paulo: Editora Unesp, 2015.

BRUNO, Adriana Rocha; TEIXEIRA, Beatriz de Basto. Inclusão Social, Inclusão Digital: O Curso de Pedagogia a Distância da Faculdade de Educação - Um Caso Brasileiro. Educação em Foco, Juiz de Fora, v. 17, n. 1, p. 151-177, mar. / jun. 2010.

CASTRO, Luciana. A Formação Continuada Docente em Juiz de Fora: "construindo a escola do Caminho Novo"? Juiz de Fora: Editora UFJF, 2013.

CURY, Carlos Roberto Jamil. Formação e conhecimento: perspectivas filosóficas e sociológicas. Avaliação, Campinas/Sorocaba, SP, v. 19, n. 3, P. 789-802, nov. 2014.

DINIZ-PEREIRA, Julio Emilio. A prática como componente curricular na formação de professores. Educação, Santa Maria, v. 36, n. 2, p. 203-218, maio/ago. 2011.

DOURADO, Luiz Fernandes. A formação de professores e a base comum nacional: questões e proposições para o debate. Revista Brasileira de Política e Administração da Educação, v. 29, n. 2, p. 367-388. Mai/ago. 2015.

FREITAS, Helena Costa Lopes de. Certificação e formação do educador: regulação e desprofissionalização. Educação e Sociedade. Campinas, SP, v. 24, n. 85, p. 1095-1124. Dez. 2003.

FREITAS, Helena Costa Lopes de. PNE e formação de professores: contradições e desafios. Revista Retratos da Escola, Brasília, v. 8, n. 15, p. 427446. Jul./dez. 2014.

FREIRE, Paulo. Pedagogia da Esperança: um reencontro com a pedagogia do oprimido. Rio de Janeiro : Paz e Terra, 1992.
FREIRE, Paulo. Pedagogia da autonomia: saberes necessários à prática pedagógica. São Paulo: Paz e terra, 1997.

GARCIA, C. M. A. Formação de professores: novas perspectivas baseadas na investigação sobre o pensamento do professor. In: NÓVOA, A. (Org.). Os professores e sua formação. Lisboa: Dom Quixote, 1999. p.51-76.

GATTI, Bernadete Angelina; BARRETO, Elba de Sá. (Coords.). Professores do Brasil: impasses e desafios. Brasília: UNESCO, 2009.

GATTI, Bernadete Angelina. Formação de Professores: compreender e revolucionar. In: GATTI, Bernadete Angelina et al. Por uma revolução no campo da formação de professores. 1. ed. São Paulo: Editora Unesp, 2015.

GATTI, Bernadete Angelina. Educação, escola e formação de professores: políticas e impasses. Educar em Revista, Curitiba, n. 50, p. 51-67. Out./dez. 2013.

GATTI, Bernadete Angelina. Formação de Professores no Brasil: características e problemas. Educação e Sociedade, Campinas, SP, v. 31, n. 113, p. 1355-1379. Out. - dez. 2010.

GATTI, Bernadete Angelina. Análise das políticas públicas para a formação continuada no Brasil, na última década. Revista Brasileira de Educação, Rio de Janeiro, v. 13, n. 37, p. 57-186. Jan./abr.2008.

GATTI, Bernadete Angelina; BARRETO, Elba de Sá, ANDRÉ, Marli. Políticas docentes no Brasil: um estado da arte. Brasília: UNESCO, 2011.

IMBERNÓN, F. Inovar o ensino e a aprendizagem na universidade. Tradução de Silvana Cobucci Leite. São Paulo : Cortez, 2011.

LAPA, Andrea; PRETTO, Nelson De Luca. Educação a distância e precarização do trabalho docente. Em Aberto, Brasília, v. 23, n. 84, p. 79-97, nov. $2010 . \quad$ Disponível em: http://emaberto.inep.gov.br/index.php/emabert o/article/view/2263/2230. Acesso em: $10 \mathrm{fev}$. 2018. 
MENEZES, Lídia Azevedo de; FILHO, Nicolino Trompieri; BRAGA, Adriana Eufrásio. Avaliação dos Orientadores de Estudo do Pacto Nacional pela Alfabetização na Idade Certa (PNAIC), Polo Iguati, Ceará. IN: CONGRESSO NACIONAL DE FORMAÇÃO DE PROFESSORES, 2.; CONGRESSO ESTADUAL PAULISTA SOBRE FORMAÇÃO DE EDUCADORES, 12., 2014. Águas de Lindóia. Anais [...]. Águas de Lindóia: UNESP, 2014. Disponível em:

http://unesp.br/anaiscongressoeducadores/Artig oAnterior?id artigo $=3267 \&$ id evento $=31$. Acesso em: 24 nov. 2017.

NÓVOA, António. Concepções e práticas de formação contínua de professores. In: CONGRESSO NACIONAL DE FORMAÇÃO CONTINUADA DE PROFESSORES: REALIDADES E PERSPECTIVAS, 1., 1991, Aveiro. Anais [...] Aveiro: Universidade de Aveiro, 1991. p. 15-18.

NÓVOA, António. A formação da profissão docente. In: NÓVOA, António. (Org.). Os professores e sua formação. Lisboa: Dom Quixote, 1995. p.15-53.

NÓVOA, António. Relação Escola-Sociedade: novas respostas para um velho problema. In: SERBINO et al. (Org.). Formação de Professores. São Paulo: Fundação Ed. UNESP, 1998. p.19-39.

NÓVOA, António. Os professores na virada do milénio: do excesso dos discursos à pobreza das práticas. Educação e Pesquisa, v. 25, n. 1, p. 1120, jan./jun. 1999. DOI: 10.1590/S151797021999000100002. Disponível em: http://dx.doi.org/10.1590/S1517-

97021999000100002. Acesso em: 20 dez. 2017.

NÓVOA, António. Firmar a posição como professor, afirmar a profissão docente. Cadernos de Pesquisa, São Paulo, v. 47, n. 166, p. 11061133, out./dez.. 2017. Disponível em: http://www.scielo.br/scielo.php?script=sci abstr act\&pid=S010015742017000401106\&lng=pt\&nr m=iso. Acesso em: 20 dez. 2017.

OLIVEIRA, Leandra Martins de. Políticas educacionais na formação de professores dos anos iniciais do Ensino Fundamental em cursos de licenciatura. Revista Ensaio: Avaliação e Políticas Públicas em Educação, Rio de Janeiro, v. 18, n. 67, p. 235-252, abr./jun.2010.
PATTO, Maria Helena Souza. A produção do Fracasso Escolar: histórias de submissão e rebeldia. 4. ed. São Paulo : Intermeios, 2015.

SARTI, Flávia Medeiros. O triângulo da formação docente: seus jogadores e configurações. Educação e Pesquisa. São Paulo, v. 38, n. 2. Abr./jun. 2012.

SCHÖN, Donald. A. Formar professores como profissionais reflexivos. In: NÓVOA, A. (Org.). Os professores e sua formação. Lisboa: Dom Quixote, 1995. p. 77-91.

SOARES, Magda. Formação de rede: uma alternativa de desenvolvimento profissional de alfabetizadores/as. Cadernos Cenpec. São Paulo, v. 4, n. 2, p. 146-173. Dez. 2014.

SOARES, Magda. Alfabetização: a questão dos métodos. São Paulo : Contexto : 2016.

SOUZA, Denise Trento Rebello de; ZIBETTI, Marli Lúcia Tonatto. Formação de professores e saberes docentes: trajetória e preocupação de uma pesquisadora da docência - uma entrevista com Ruth Mercado. Educação e Pesquisa, São Paulo, v. 40, n. 1, p. 247-267. Jan./mar. 2014. Disponível em: http://www.scielo.br/pdf/ep/v40n1/16.pdf. Acesso em 03 dez. 2016.

TARDIF, Maurice; LESSARD, Claude. 0 trabalho docente: elementos para uma teoria da docência como profissão de interações humanas. Tradução de João Batista Kreuch. Petrópolis, RJ : Vozes, 2008.

VAILLANT, Denise. Para uma mudança radical na formação inicial de professores. In: GATTI, Bernardete Angelina et al. Por uma revolução no campo da formação de professores. 1. ed. São Paulo: Editora Unesp, 2015.

Submetido: 09/09/2018

Correções obrigatórias: 29/11/2018

Aceite final: 09/12/2018 